\title{
Underwater behaviour of green turtles monitored with video-time-depth recorders: what's missing from dive profiles?
}

\author{
Jeffrey A. Seminoff ${ }^{1, *}$, T. Todd Jones ${ }^{2}$, Greg J. Marshall ${ }^{3}$ \\ ${ }^{1}$ NOAA - National Marine Fisheries Service, Southwest Fisheries Science Center, 8604 La Jolla Shores Dr., La Jolla, \\ California 92037, USA \\ ${ }^{2}$ Department of Zoology, University of British Columbia, 6270 University Blvd, Vancouver, BC, V6T 1Z4, Canada \\ ${ }^{3}$ Remote Imaging Division, National Geographic Society, 1145 17th Street, NW Washington, DC, 20036-4688, USA
}

\begin{abstract}
We used a turtle-mounted video and data-logging system (Crittercam; National Geographic Society, USA) to study underwater behaviour and dive patterns of green turtles, Chelonia mydas, at a coastal foraging area in the Gulf of California, Mexico. Between August 1997 and June 2002, units were deployed 36 times on 34 green turtles ranging from 64.1 to $96.7 \mathrm{~cm}$ in straight carapace length and 38.6 to $120.5 \mathrm{~kg}$ in weight. A total of $89.5 \mathrm{~h}$ of video was recorded with corresponding dive data (1065 total dives). Foraging was observed during 8 deployments (28 events) at depths of 3.0 to $32.0 \mathrm{~m}$ and occurred while turtles were swimming in the midwater column and stationary on the seafloor; 4 marine algae and 5 invertebrate prey species were identified. Resting behaviour was seen during 9 deployments (33 dives) as turtles set on the seafloor at depths of 7.0 to $26.5 \mathrm{~m}$. Overall, 6 dive types were observed and labeled Type 1 to Type 6 dives. Green turtles foraged during Type 1, Type 3, and Type 5 dives, whereas they rested only during Type 1 dives. In addition to elucidating the importance of specific habitats and resources in neritic foraging areas, our results confirm that a variety of underwater behaviours can be reflected by 1 specific dive profile. These data indicate caution should be exercised when ascertaining in-water activity solely based on the appearance of dive profiles.
\end{abstract}

KEY WORDS: Behaviour - Dive type $\cdot$ Chelonia mydas $\cdot$ Crittercam $\cdot$ Habitat use $\cdot$ Green turtle VTDR

\section{INTRODUCTION}

Two fundamental aspects of sea turtle behavioural ecology concern how individuals forage and rest within neritic habitats. Although the timing and location of these activities have been the focus of prior research, few data are available, primarily because sea turtles are difficult to observe underwater. Most studies have relied on indirect measurements via turtle-mounted electronic devices such as time-depth recorders (TDRs) and acoustic transmitters (e.g. Schmid et al. 2002, Seminoff et al. 2002a, Southwood et al. 2003). Studies utilizing these techniques often describe in-water activity subjectively according to dive profiles and dive duration. Whereas dives of short duration and those with continuous depth fluctuations during the bottom phase are believed to represent foraging (e.g. Brill et al. 1995, van Dam \& Diez 1996, Makowski et al. 2006), longer dives to a fixed depth (i.e. U-shaped dive profile) have been considered resting dives (e.g. Hochscheid et al. 1999, Hays et al. 2000, Southwood et al. 2003). These inferences suggest that dive profiles are useful for interpreting underwater activity of seaturtles in coastal foraging areas. However, the exclusive use of time-depth plots yields an empirical view of sea turtle dive behaviour, void of any information on the interaction between tracked subjects and their environment. 


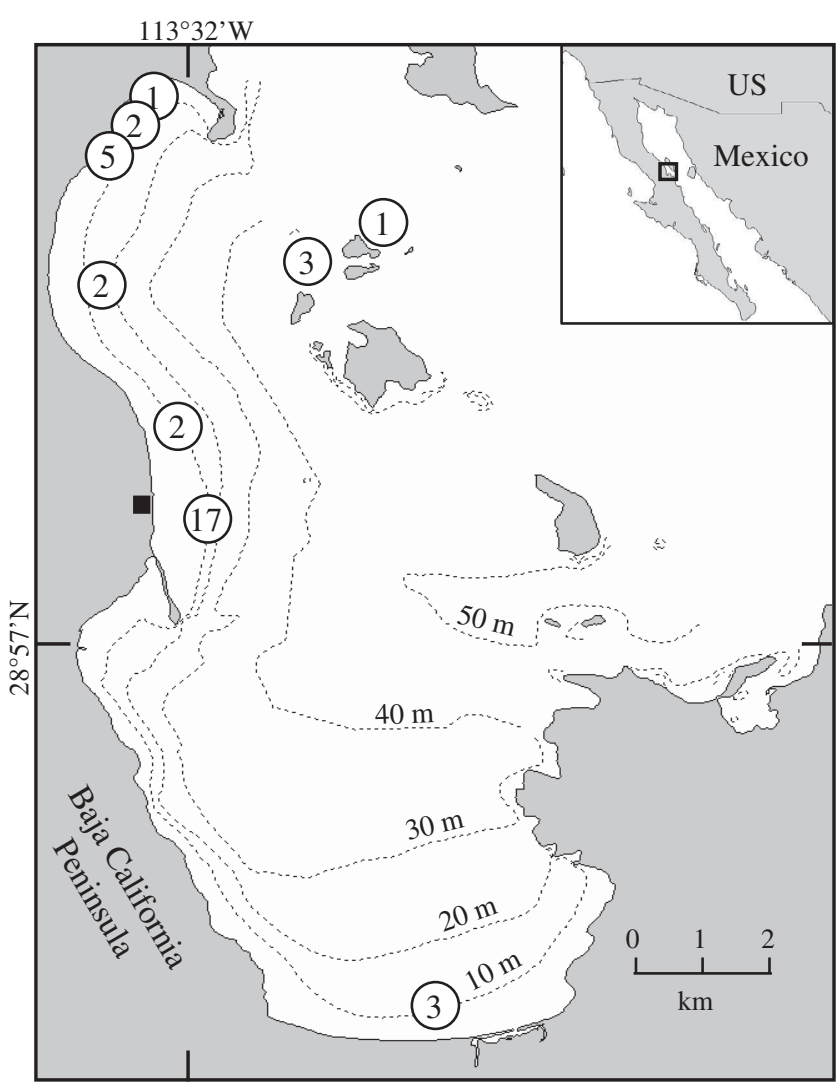

Fig. 1. Map of Bahía de los Angeles study area along the eastern coast of the Baja California Peninsula, Mexico. Circles with numbers indicate capture/release sites for Crittercam deployments. The numbers represent number of VTDR deployments at each capture/release site. Dashed lines indicate $10 \mathrm{~m}$ baythmetric contours. See Appendix 1 for deployment location of each individual

Over recent years, the use of animal-borne video systems that integrate TDR technology (VTDRs) has proven useful for studying the behaviours of freeswimming sea turtles (Heithaus et al. 2002b, Reina et al. 2005). In addition to producing information on a turtle's interaction with marine habitats, these systems enable researchers to link dive profiles and depths with an array of underwater activities. VTDR systems are thus able to provide insights into the variability in behaviours that are reflected by a given dive profile.

The green turtle (Chelonia mydas) is prime candidate for the application of VTDR technology. This species is a resident of temperate and tropical marine habitats around the world (e.g. Musick \& Limpus 1997), and its coastal occupancy enables feasible deployment and recovery of VTDR systems, which must be retrieved to access collected data. Green turtles consume vast quantities of marine algae and seagrasses, and the resultant digestive processing constitutes an important conduit for energy flow in coastal ecosystems (e.g. Thayer et al. 1982, Bjorndal 1997). Elucidating the patterns of prey acquisition and habitat use will help specify the value of marine resources for this large omnivore and will lead to greater knowledge of the structure and function of coastal marine ecosystems.

In this study, we used a turtle-mounted VTDR system (Crittercam, National Geographic Society, Washington DC) to monitor the behaviours of submerged green turtles at a temperate foraging area in the Gulf of California, Mexico. Our primary objectives were to (1) describe the foraging and resting strategies of this species through video analysis and (2) link these observations with time-depth plots to elucidate the value of dive profiles for determining underwater behaviour. This is the first study using VTDRs to monitor the behaviours of hard-shelled turtles in the eastern Pacific Ocean. When combined with conventional telemetry and dietary studies (e.g. Seminoff et al. $2002 a, b)$, we believe the application of video technology will generate an enhanced view of green turtle ecology.

\section{MATERIALS AND METHODS}

Between August 1997 to June 2002 we attached VTDR systems 36 times on 34 green turtles captured with entanglement nets during an ongoing study of green turtle demography at Bahía de los Angeles $\left(28^{\circ} 58^{\prime} \mathrm{N}, 113^{\circ} 33^{\prime} \mathrm{W}\right.$; Fig. 1) in the Gulf of California, Mexico (Seminoff et al. 2003). Turtles selected for instrumentation were captured among 9 sites throughout the study area (Fig. 1), and they ranged from 64.1 to $96.7 \mathrm{~cm}$ (mean $=79.6 \pm 1.5 \mathrm{~cm})$ in straight carapace length (SCL) and from 38.6 to $120.5 \mathrm{~kg}$ (mean = 75.1 \pm $4.1 \mathrm{~kg}$ ) in body weight (Appendix 1). Although 2 turtles were missing large portions of a front flipper, all turtles otherwise appeared to be in fine health. VTDR-fitted turtles were released at their site of initial capture within $24 \mathrm{~h}$.

VTDR technology. The VTDR system consisted of a Hi-8 video camera integrated with a time-depth recorder and on-board microcomputer $(512 \mathrm{~kb}$ of memory). These components were packaged in a cylindrical aluminum housing (diameter: $10.1 \mathrm{~cm}$; length: $31.7 \mathrm{~cm}$ ) that had a hydrodynamically optimized dome and conical tail portion composed of incompressible syntactic foam (Fig. 2). Five different units were used during this study. For recovery, these units were equipped with a very-high-frequency (VHF) radio transmitter (MOD 050, Telonics, Mesa, AZ, USA) and acoustic (ultrasonic) tag (CHP-87-L, Sonotronics, Tucson, AZ). VTDRs weighed $2 \mathrm{~kg}$ out of the water (1.7 to $5.2 \%$ of turtle body weight), but were slightly posi- 


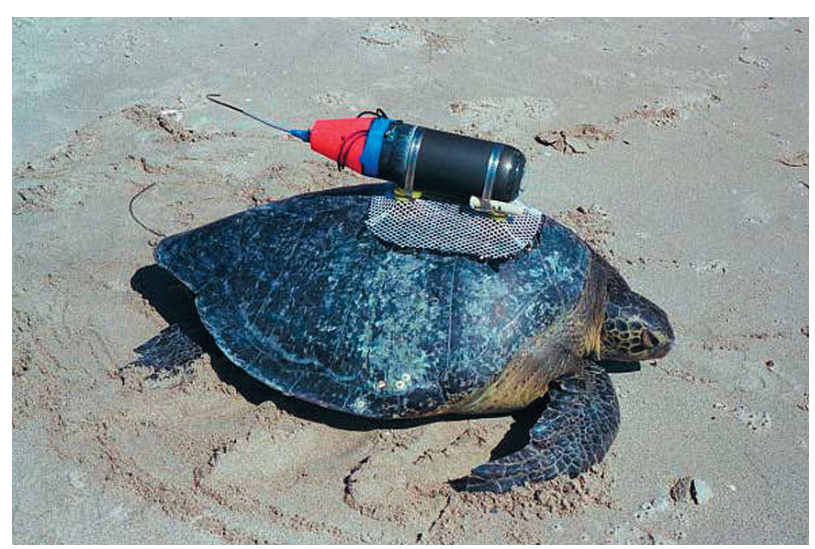

Fig. 2. Chelonia mydas. Green turtle (BLA 511) in Bahía de los Angeles equipped with a VTDR (Crittercam, National Geographic Society, Washington, DC). Whereas this turtle was $68.1 \mathrm{~cm} \mathrm{SCL}$, the size range of all turtles examined during this study was 64.1 to $96.7 \mathrm{~cm} \mathrm{SCL}$

tively buoyant in water; however, this buoyancy was rendered neutral during deployments due to the attachment of counterweights on the attachment base plate (see below). We programmed VTDRs to collect audio and video in both short-play ( $3 \mathrm{~h}$ ) and long-play (6 h) modes and to record continuously or at a $5 \mathrm{~min}$ on/5 min off duty cycle. Pressure (i.e. water depth) data were collected at a range of intervals between 2 to 7 s. Depth measurement resolution and maximum depth were 0.5 and $500 \mathrm{~m}$, respectively. The units were calibrated in a standard pressure facility at the National Geographic Society Remote Imaging Laboratory, Washington, DC, USA.

We attached VTDRs to the crown of each turtle's carapace with a 2-plate mechanism: the top plate was connected to the housing with 2 hose clamps; the bottom plate was fitted with a nylon-mesh apron, and attached to the carapace with 5 min quick-set epoxy. The front of these plates was connected by an interlocking assembly, and the back was linked with a burn-wire connector and backup corrosive (Mg) link. VTDRs were programmed to detach 3 to $20 \mathrm{~h}$ after deployment, at which time a charge from an on-board $9 \mathrm{~V}$ battery was sent to the burn-wire, causing the wire to corrode and break, thereby disengaging the plates. Once detached from the counterweighted baseplate, the slight positive buoyancy of the VTDR brought it to the surface. For 11 of the 36 deployments, we tracked turtles for the entire deployment duration following protocol described in Seminoff et al. (2002a). Surfacing positions and times were recorded for calculation of swim speed and total distance traveled.

Video and data analysis. Video images were copied from Hi-8 format to VHS format, then time-stamped and viewed using a standard VCR. We described 4 primary classes of turtle activity: surfacing, travelling, foraging, and resting. Surfacing events were coded when a turtle's head broke the surface of the water and included activity while the water's surface could be seen in the video. Travelling was recorded for turtles undertaking 'midwater' dives with no visits to benthic substrata. Foraging was inferred when (1) a specific food item was seen ingested by a turtle, (2) an item in the video went out of view and was followed immediately by chewing motions, often accompanied by sound of mastication, or (3) fragments of a prey item were seen expelled though the external nares of the turtle. All ingested items that could be seen were identified to the lowest taxon. Handling times for each food item were calculated as the interval from when a turtle engaged with a prey item to when all apparent food intake (i.e. mastication) ceased. We determined the depth of each foraging event and summarized foraging depth as the number of events in each of five $10 \mathrm{~m}$ depth categories $(0$ to $50 \mathrm{~m}$ ) that reflect the depths within the study area. A turtle was coded as resting when it appeared motionless with no apparent head or flipper movements.

Depth data were graphed using the program LiteShow (Onset Computers, Bourne, MA, USA). All vertical movements to $\geq 1.5 \mathrm{~m}$ depth were considered dives. We characterized each dive visually by the general shapes of descent, bottom, and ascent phases of time-depth plots. We also calculated depth (m) and duration (min) for each dive. Depth was defined as the deepest point on the dive profile. To determine dive duration, we defined the beginning and end of dives as the first of 3 successive data samples of increasing depth to below $1.5 \mathrm{~m}$ and the last of a set of 3 ascending data points of decreasing depth to above $1.5 \mathrm{~m}$, respectively. We used linear regression to examine the relationships of mean depth versus mean duration among turtles for each dive type, as well as turtle size (log weight) versus dive depth and dive duration. Analyses of variance (ANOVA) were used to compare dive type with mean depth and mean duration among turtles, and to compare depths of dives containing foraging and resting. For turtles that exhibited continuous resting dives, we used the mean depth and mean duration of the respective continuous dive sequence for the analyses. A Tukey-Kramer HSD post-hoc test was used to determine significant differences among mean depths and durations for each dive type. Only dives with concurrent video were included in analyses. Although it is common practice to exclude the early portions of dive and video data subsequent to deployment, we analyzed all data since several behaviours were observed during the earliest portions of each deployment. Statistical analysis was performed with 
Table 1. Summary of dive data for 25 video-time-depth recorder deployments on green turtles in Bahía de los Angeles. Only dive data for which concurrent video was collected are given. Analyses are based on means from each deployment. Results of the Tukey HSD test: means having at least 1 superscript in common are not significantly different

\begin{tabular}{|c|c|c|c|c|c|c|}
\hline Dive characteristics & Type 1 & Type 2 & Type 3 & Type 4 & Type 5 & Type 6 \\
\hline No. of deployments & 19 & 26 & 12 & 17 & 22 & 9 \\
\hline No. of dives with video & 71 & 561 & 52 & 109 & 234 & 38 \\
\hline Mean dive depth (m) & $20.0 \pm 3.3^{\mathrm{a}}$ & $14.1 \pm 2.3^{\mathrm{b}}$ & $10.3 \pm 1.7^{\mathrm{b}}$ & $13.7 \pm 2.9^{b}$ & $7.0 \pm 1.3^{\mathrm{b}}$ & $18.5 \pm 2.8^{\mathrm{a}}$ \\
\hline Mean dive depth range (m) & $7.0-47.8$ & $3.3-41.5$ & $3.5-25.9$ & $5.1-26.6$ & $3.1-17.6$ & $4.7-31.8$ \\
\hline Mean dive duration (min) & $12.6 \pm 1.4^{\mathrm{a}}$ & $4.3 \pm 0.7^{\mathrm{b}}$ & $8.2 \pm 1.6^{\mathrm{a}, \mathrm{b}}$ & $10.0 \pm 2.4^{\mathrm{a}}$ & $4.5 \pm 0.8^{\mathrm{b}}$ & $9.5 \pm 5.3^{\mathrm{a}}$ \\
\hline Mean dive duration range (min) & $7.0-26.1$ & $1.6-16.0$ & $3.0-25.3$ & $4.0-28.1$ & $2.0-11.3$ & $3.4-21.0$ \\
\hline Depth $(x)$ vs duration $(y)$ & $y=0.22 x+8.11$ & $y=0.27 x+1.11$ & $y=0.70 x+2.45$ & $y=0.69 x+2.35$ & $y=0.56 x+1.44$ & $y=0.42 x+3.35$ \\
\hline Regression statistics & $\begin{array}{c}F_{1,18}=4.23 \\
\mathrm{R}^{2}=0.28 \\
\mathrm{p}=0.06\end{array}$ & $\begin{array}{c}F_{1,25}=52.39 \\
\mathrm{R}^{2}=0.72 \\
\mathrm{p}<0.001\end{array}$ & $\begin{array}{c}F_{1,11}=14.29 \\
\mathrm{R}^{2}=0.54 \\
\mathrm{p}=0.003\end{array}$ & $\begin{array}{c}F_{1,16}=16.36 \\
\mathrm{R}^{2}=0.67 \\
\mathrm{p}=0.004\end{array}$ & $\begin{array}{c}F_{1,21}=48.29 \\
\mathrm{R}^{2}=0.81 \\
\mathrm{p}<0.001\end{array}$ & $\begin{array}{c}F_{1,8}=32.84 \\
\mathrm{R}^{2}=0.73 \\
\mathrm{p}<0.001\end{array}$ \\
\hline Observed foraging activity & Yes & No & Yes & No & Yes & No \\
\hline Observed resting activity & Yes & No & No & No & No & No \\
\hline
\end{tabular}

JMP software (SAS Institute 1996). Values for significance were set at $p<0.05$. Mean values are given \pm standard error (SE).

\section{RESULTS}

\section{Deployment and tracking summary}

The deployment durations of VTDRs ranged from 0.3 to $20.0 \mathrm{~h}$ (mean $=4.6 \pm 0.74 \mathrm{~h}$ ). Video and dive data were successfully recorded during 30 deployments and 27 deployments, respectively. On several deployments, camera and/or electrical malfunctions prevented data collection or caused premature detachment (Appendix 1). VTDR deployments occurred primarily during daylight periods (06:00 to 19:30 h) with $98.3 \%$ of video and $93.5 \%$ of dive data collected during this interval. Among the deployments during which turtles were tracked continuously $(\mathrm{n}=11)$, track lengths ranged from 2.6 to $12.7 \mathrm{~km}$ (mean $=5.6 \pm$ $1.0 \mathrm{~km}$ ), resulting in mean swimming speeds of 0.9 to $2.0 \mathrm{~km} \mathrm{~h}^{-1}$ (overall mean $=1.4 \pm 0.1 \mathrm{~km} \mathrm{~h}^{-1}$ ).

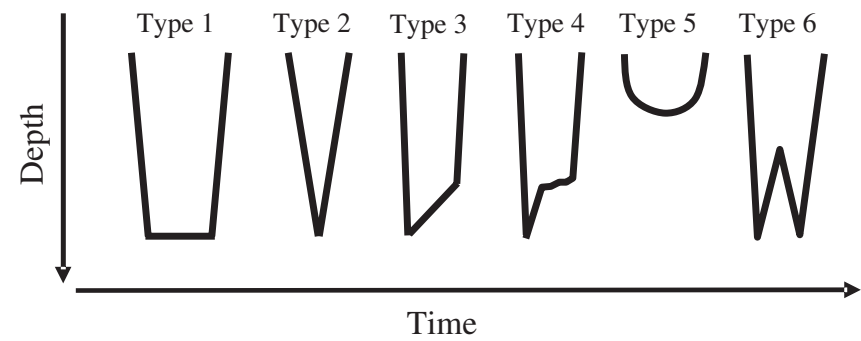

Fig. 3. Generalized profiles for the 6 dive types undertaken by green turtles

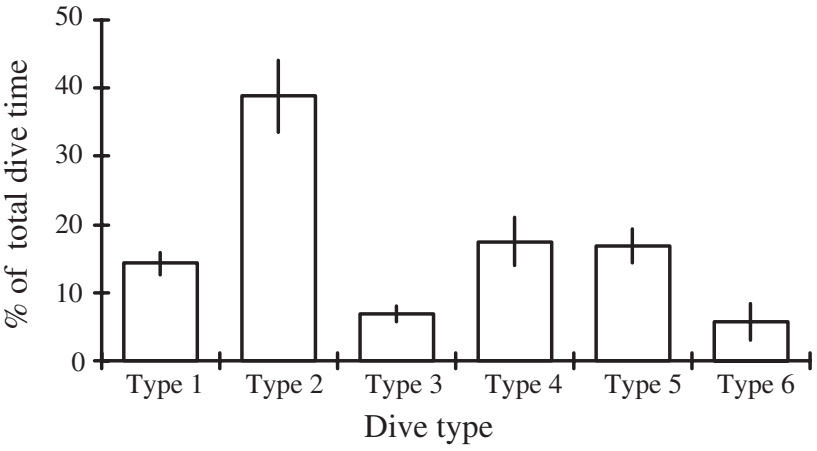

Fig. 4. Proportion of total dive time for each dive type

\section{Dive patterns}

A total of 1065 dives (93.8\% of all dives) had corresponding video (Table 1). Green turtles conducted from 6 to 128 dives per deployment. We observed 6 different dive types; a generalized profile for each type is presented in Fig. 3. To maintain consistency with previous sea turtle diving studies, we labeled dives following terminology from Minamikawa et al. (1997) and Houghton et al. (2002). These included Type 1, Type 2, Type 3, Type 4, and Type 5. We also observed a sixth dive type (Type 6) that, although shown graphically (Southwood et al. 2003, Reina et al. 2005), has not been labeled previously. Type 6 dives were $\mathrm{W}$-shaped, with the initial descent followed by an ascent of $\geq 2 \mathrm{~m}$, then a second descent of $\geq 2 \mathrm{~m}$ before the final ascent to the surface. This dive profile reflected midwater dives ( $\mathrm{n}=$ $27)$ and dives to the seafloor $(n=11)$.

Table 1 summarizes the frequency, depth, duration, and turtle activities for each dive type. Type 2 dives comprised the greatest proportion of total dive time, 
whereas Type 3 and Type 6 dives constituted the smallest proportions of total dive time (Fig. 4). Maximum dive depth and dive duration for each deployment ranged from 11.0 to $54.5 \mathrm{~m}($ mean $=28.4 \pm 2.1 \mathrm{~m})$ and from 5 to $48 \mathrm{~min}$ (mean $=16.1 \pm 1.7 \mathrm{~min})$, respectively; there was no significant relationship between turtle weight and maximum dive depth $(\mathrm{p}=0.86)$ or maximum dive duration $(p=0.36)$. The relationships between mean dive depth and mean dive duration were significant for all dive types except Type 1 dives, although the latter was only marginally non-significant ( $p=0.06$, Table 1$)$. Among dive types, there were significant differences in mean dive depths $\left(F_{1,5}=3.54\right.$, $\mathrm{p}=0.006)$ and mean dive durations $\left(F_{1,5}=6.40, \mathrm{p}<\right.$ 0.001). Type 1 and Type 6 dives were significantly deeper than Type 5 dives; and Type 1, Type 4, and Type 6 dives were significantly longer than Type 2 and Type 5 dives (Tukey HSD, $\mathrm{p} \leq 0.05$ ).

\section{Linking video with dive data}

A total of $89.5 \mathrm{~h}$ of video ( $86.4 \%$ of all video) had corresponding dive data. The most common activities observed in the video were surfacing and travelling movements. During travelling, the video often depicted the turtle's fully extended neck and head bobbing in conjunction with flipper strokes (Fig. 5a); green turtles would occasionally move their head from side to side in apparent attempts to survey the water column. Amidst travelling dives, green turtles would occasionally undertake exploratory Type 2 dives to the seafloor to survey benthic habitats (Fig. 6a).

Twenty-eight feeding events were observed on video among 8 deployments. Prey handling times ranged from 0.1 to $6.9 \mathrm{~min}$ overall, resulting in $51.4 \mathrm{~min}$ of foraging activity among all deployments (Table 2). From 0 to 16 foraging events occurred in each $10 \mathrm{~m}$ depth class. The greatest proportion of feeding occurred in the 0 to $9.9 \mathrm{~m}$ depth class, with a lesser peak in the 20.0 to $29.9 \mathrm{~m}$ depth class (Fig. 7). The initial feeding bouts during each deployment occurred $6.2 \mathrm{~min}$ to $10.7 \mathrm{~h}$ after release. Low-light conditions and/or turtle-head silhouettes obscured the view on 7 feeding events. Of the prey items that were clearly seen, 4 marine algae species and 5 invertebrates were identified (Table 2).

We observed 3 foraging strategies: stationary foraging ( $\mathrm{n}=22$ events), active benthic foraging ( $\mathrm{n}=4$ events), and active midwater foraging ( $\mathrm{n}=2$ events). Stationary foraging occurred at depths of 3.5 to $32.0 \mathrm{~m}$ as turtles sat on the seafloor during Type 1 dives. This foraging strategy was associated with algae pastures, mixed algae/gorgonian (Gorgoniidae) fields, black coral (Antilopathes galapagensis) patches, and deep- water anoxic substrate zones. The latter habitat hosted a previously undescribed stationary foraging tactic: during 7 Type 1 dives to greater than $25 \mathrm{~m}$, green turtles were seen making head lunges into anoxic small-particle substrate, expelling silt-laden water through their nostrils while showing head movements consistent with mastication (Fig. 6b see video at: www.int-res.com/articles/suppl/m322p269_videos/).

Solitary tube worms (Bispira sp.) were the confirmed prey species during 2 of these 'benthic sifting' events. Other foods consumed during stationary foraging included marine algae (Rhodophyta and Chlorophyta; Table 2, Fig. 5c,d), and black coral polyps (Table 2). Active benthic foraging occurred during Type 1 dives as turtles moved along sandy benthic substrates at depths of 4.5 to $27.0 \mathrm{~m}$. The foods consumed during these active benthic foraging events included sea pens (Ptilosarcus undulatus; Table 2, Fig. 5e,f) and algae fragments. Active midwater foraging targeted prey in the water column and occurred during the initial ascent of a Type 3 dive at a depth of $8.0 \mathrm{~m}$ (consumption of Sargassum sp.; Table 2, Figs 5b \& 6c) and during the ascent of a Type 5 dive at a depth of $5.0 \mathrm{~m}$ (consumption of a Scyphozoan; Table 2, Fig. 6d).

We recorded 33 resting dives that ranged from 12.5 to $26.0 \mathrm{~m}$ in depth. Green turtles ranging from 38.6 to $85.9 \mathrm{~kg}$ were observed resting, but the relationship between turtle weight and resting dive duration was not significant ( $p=0.83$ ), nor was the relationship between turtle weight and resting dive depth $(\mathrm{p}=$ $0.67)$. Resting occurred during periods that encompassed $\geq 2$ sequential Type 1 dives ('continuous resting'; $\mathrm{n}=2$ to 14 dives per resting sequence, 4 deployments; Fig. 6e) and during single Type 1 dives ('episodic resting'; $\mathrm{n}=9$ deployments; Fig. 6f). Continuous resting dives occurred during early afternoon (13:00 to $15: 00 \mathrm{~h}, \mathrm{n}=16$ dives), late afternoon (17:30 to 19:00 $\mathrm{h}, \mathrm{n}=3$ dives), and nocturnal periods (22:30 to $05: 00, \mathrm{n}=3$ dives). These dives ranged from 4.2 to $23.6 \mathrm{~min}($ mean $=13.1 \pm 2.8 \mathrm{~min})$ in duration and occurred as turtles sat motionless on the seafloor within patches of black coral ( $\mathrm{n}=17$ dives), marine algae pastures dominated by Padina durvillaei ( $\mathrm{n}=3$ dives; Fig. $5 \mathrm{~g}$ ), and insular boulder habitats ( $\mathrm{n}=2$ dives). All episodic resting dives occurred during early afternoon (13:00 to $15: 00 \mathrm{~h}$ ) and ranged from 1.8 to $22.5 \mathrm{~min}$ in duration $($ mean $=11.9 \pm 1.1 \mathrm{~min})$. During episodic resting, turtles sat on the sea floor within black coral patches ( $\mathrm{n}=7$ dives; Fig. $5 \mathrm{~h}$ ) and boulder habitats ( $\mathrm{n}=$ 4 dives). Overall, green turtles rested for $130.9 \mathrm{~min}$ during episodic resting dives, and 288.2 min during continuous resting dives. No turtle was seen wedging itself within vertical features and no turtle was observed resting in the midwater column amidst dives.

Type 1 dives had the greatest number of associated 

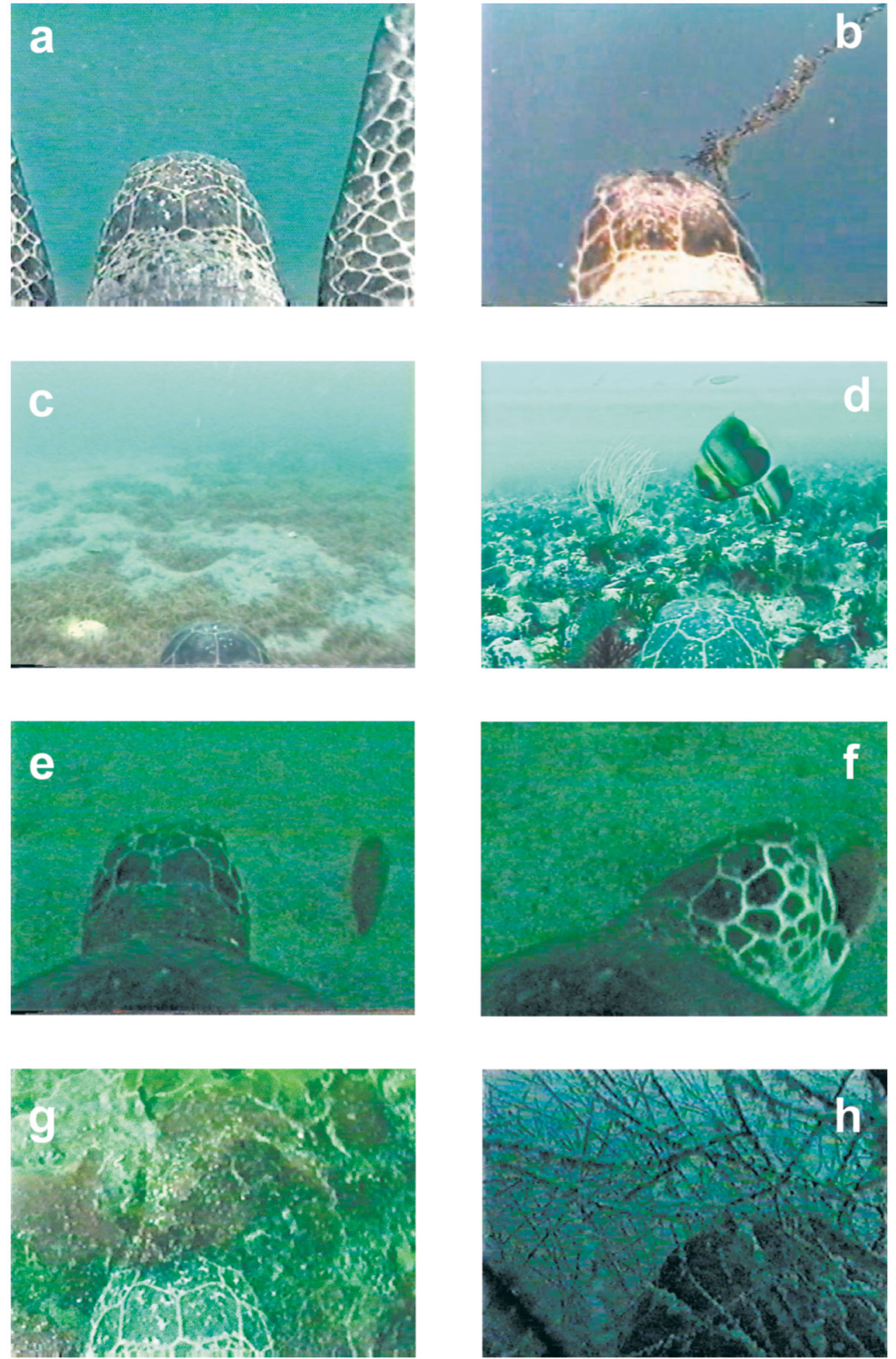

Fig. 5. Chelonia mydas. Video frames collected by Crittercam: (a) traveling movements, CM-4; (b) active midwater foraging on Sargassum sp., CM-24; (c) stationary benthic foraging at Gracilariopsis pasture, CM-26; (d) stationary benthic foraging at mixed algae/gorgonian pasture, CM-14; (e,f) active benthic foraging on sea pen Ptilosarcus undulatus, CM-20 (images recorded $3 \mathrm{~s}$ apart); (g) continuous resting in Padina durvillaei pasture, CM-4; (h) episodic resting in a patch of black coral Antipathes galapagensis, CM-5. Video clips from which each image was taken, as well as additional clips, are available at: www.int-res.com/articles/suppl/m322p269_videos/ 

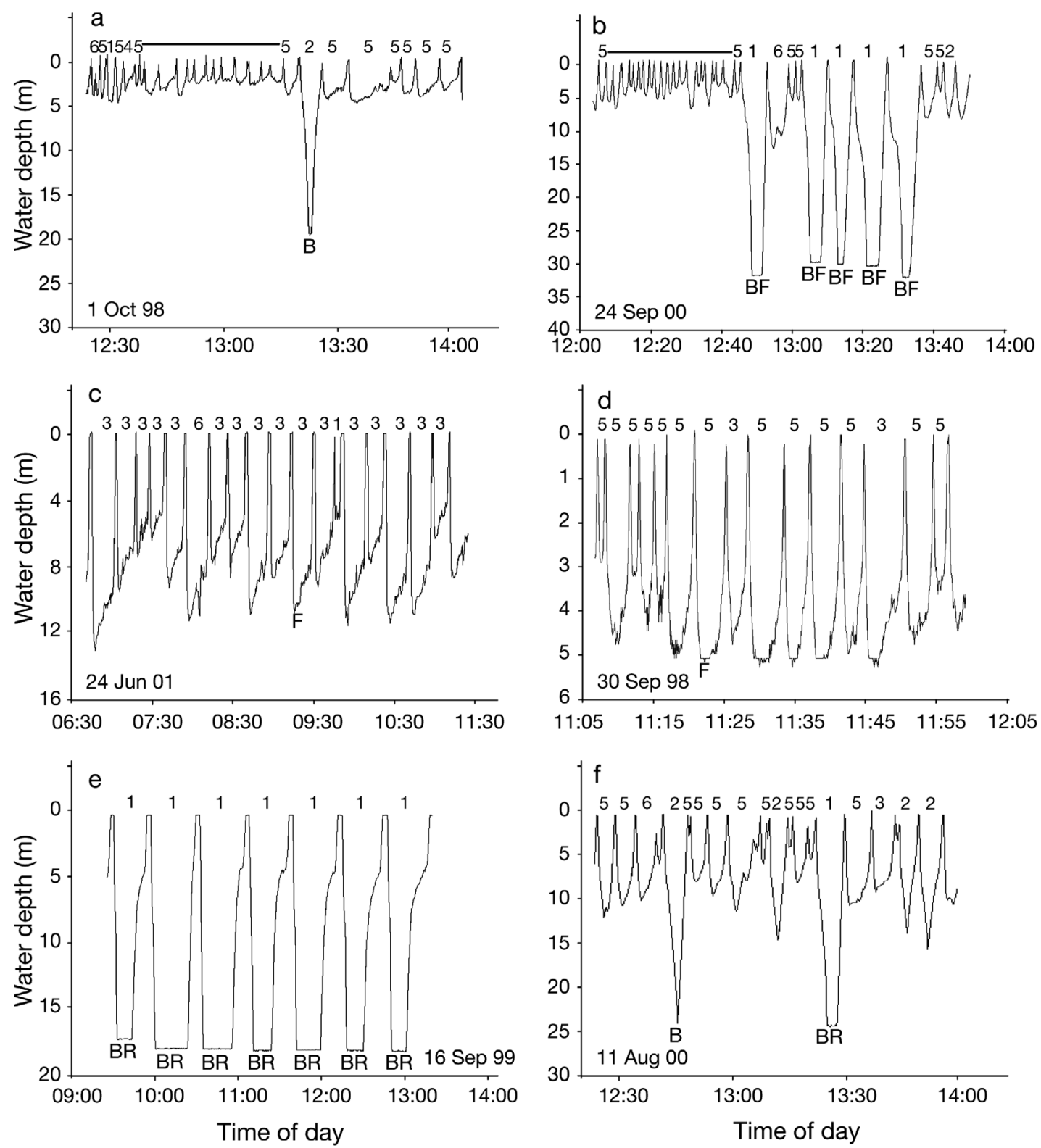

Fig. 6. Examples of dive-profile sequences that had corresponding video footage: (a) exploratory Type 2 dive (to ca. $20 \mathrm{~m}$ ) amidst shallow dives; (b) Type 1 dives (to ca. $30 \mathrm{~m}$ ) with benthic foraging amidst shallow dives; (c) Type 3 dives with midwater foraging event; (d) Type 5 dives with midwater foraging event; (e) continuous resting Type 1 dives, (f) variable dives with a benthic exploratory Type 2 dive and an episodic resting Type 1 dive. Numerals above each dive profile indicate the dive type; letters below dive profiles indicate underwater activity: $B=$ benthic dive, $F=$ foraging, $R=$ resting

underwater activities of all dive types. Of the 71 Type 1 dives with corresponding video, 11 were episodic resting dives, 22 were part of continuous resting sequences, 25 included horizontal movements along the seafloor without foraging, and 13 contained foraging (Table 3). Among these 4 activity classes there was no evidence of a difference in dive depths $\left(F_{3,51}=0.96, \mathrm{p}=\right.$ 0.42 ) but there was a difference in dive durations $\left(F_{3,51}=7.06, \mathrm{p}<0.001\right)$. Continuous and episodic resting Type 1 dives were significantly longer than both movement and foraging Type 1 dives; foraging Type 1 dives were significantly shorter an all other Type 1 dives (Tukey HSD, $\mathrm{p} \leq 0.05$ ).

\section{DISCUSSION}

Despite the increasingly widespread application of telemetry techniques to study sea turtle activity, published information on the behavioural patterns and habi- 
Table 2. Diet items seen on video during VTDR deployments. If prey item was consumed on more than 1 occasion, depth and handling time $\left(T_{\mathrm{h}}\right)$ are given as ranges. $\mathrm{B}=$ benthic foraging; $\mathrm{M}=$ foraging in the midwater column

\begin{tabular}{|c|c|c|c|c|c|}
\hline Prey item & Common name & Depth (m) & Location & $T_{\mathrm{h}}(\min : \mathrm{s})$ & No. of events \\
\hline \multicolumn{6}{|l|}{ Chlorophyta } \\
\hline Ulva lactuca & Sea lettuce & 4.5 & B & $01: 20$ & 1 \\
\hline \multicolumn{6}{|l|}{ Phaeophyta } \\
\hline Sargassum johnstonii & Sargassum & 3.0 & M & $00: 23$ & 1 \\
\hline \multicolumn{6}{|l|}{ Rhodophyta } \\
\hline Gracilariopsis lemaneiformis & Red algae & 8.0 & B & 00:34-06:01 & 2 \\
\hline Gigartina sp. & Red algae & $7.5-9.0$ & B & $04: 22-06: 54$ & 3 \\
\hline Unidentified marine alga & Algae & $4.5-17.0$ & B & $00: 08-00: 30$ & 5 \\
\hline \multicolumn{6}{|l|}{ Cnidaria } \\
\hline Scyphozoa (Medusa) & Sea jelly & 5.5 & M & 00:03 & 1 \\
\hline Ptilosarcus undulatus & Fleshy sea pen & 27.0 & $\mathrm{~B}$ & 00:05 & 1 \\
\hline Antipathes galapagensis & Yellow-polyp black coral & $18.0-23.5$ & $\mathrm{~B}$ & $02: 10-05: 36$ & 3 \\
\hline Lytocarpus nuttingi & Hydroid & 24.5 & B & $00: 50$ & 1 \\
\hline \multicolumn{6}{|l|}{ Annelida } \\
\hline Bispira sp. & Fanworm & $5.5-32.0$ & B & $00: 07-01: 21$ & 3 \\
\hline Unidentified & & $4.5-32.0$ & B & $00: 03-02: 24$ & 7 \\
\hline
\end{tabular}

tat use of free-ranging sea turtles is scarce. The present VTDR application represents one of the few studies of sea turtles employing this technology (see also Heithaus et al. 2002b, Reina et al. 2005). Overall we were successful in describing 6 general dive patterns (i.e. Type 1 to Type 6 dives) and 8 underwater behaviours: (1) midwater travelling, (2) benthic exploration, (3) horizontal movements along the seafloor, (4) active midwater foraging, (5) active benthic foraging, (6) stationary benthic foraging, (7) continuous resting, and (8) episodic resting. Green turtles engaged in these behaviours while interacting with 7 habitat types. Linking these data has elucidated ecological aspects of green turtles at a warm temperate foraging area and has contributed to our general knowledge about the variability of green turtle behaviours during submergence.

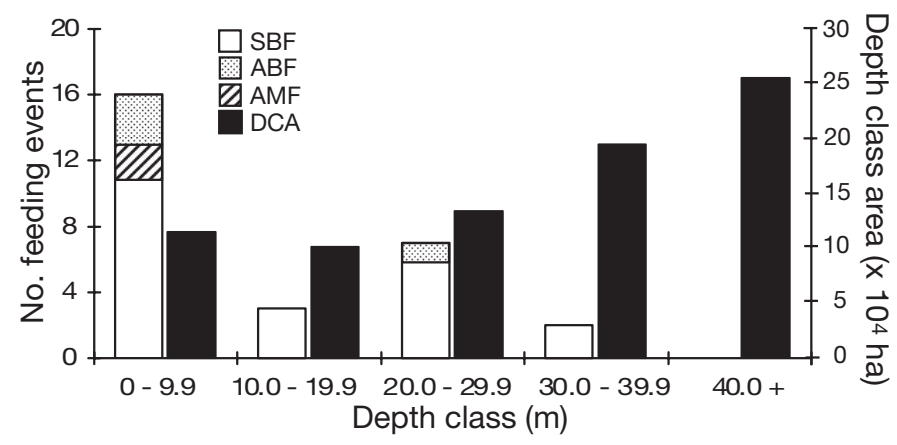

Fig. 7. Frequency of foraging events summarized by $10 \mathrm{~m}$ depth classes. SBF: stationary benthic foraging; ABF: active benthic foraging; AMF: active midwater foraging. Prey species were identified during 21 of the 28 feeding events (see Table 4). DCA: corresponding area (ha) of depth class within Bahía de los Angeles

\section{Dive profiles versus underwater activity}

The dive profiles exhibited by green turtles were consistent with those previously reported for hardshelled sea turtles, although we found a greater diversity of behaviours during the respective dive types. For example, whereas Type 1 dives are often attributed to resting (e.g. van Dam \& Diez 1996, Hays et al. 2000, Southwood et al. 2003), we also observed active and stationary benthic feeding as well as horizontal movements in video from these dives. Variation in dive activity was also seen during Type 2, Type 3, Type 5, and Type 6 dives, all of which have commonly been linked to orientation and travelling movements (e.g. Hochscheid et al. 1999, Hays et al. 2001, Houghton et al. 2002). In addition to the travelling, green turtles were observed visiting benthic habitats during apparent exploratory behaviour during Type 2 and Type 6 dives, and they were seen actively foraging in the midwater column during Type 3 and Type 5 dives. The potential for multiple behaviours to be reflected by a single dive profile type has been suggested elsewhere (van Dam \& Diez 1996, Minamikawa et al. 1997, Hochscheid \& Wilson 1999, Hochscheid et al. 1999), but few data are available due to the paucity of direct field observations. In the Mediterranean Sea, Houghton et al. (2000) observed loggerhead turtles (Caretta caretta) consuming mollusks in benthic habitats during dives that would be interpreted as resting dives. Heithaus et al. (2002b) used VTDRs to show that Australia green turtles exhibit a novel rubbing behaviour on sponge outcrops during dives that would normally be considered foraging dives. Coupled with these find- 
ings, our results indicate that caution should be used when ascertaining the function of individual dives based solely upon their time-depth plots.

\section{Foraging strategies}

By revealing novel diet items and elucidating the strategies undertaken by green turtles to consume prey, VTDR systems complement conventional diet study techniques such as esophageal lavage and fecal analysis. The consumption of 9 different prey species was seen in the video, including two (Sargassum sp. and annelid worms) that were previously described as incidental diet items (Seminoff et al. 2002b; Table 2). Also included in this group was a Scyphozoan, the first gelatinous prey described for green turtles in the region despite extensive dietary research (Seminoff et al. $2002 b$, unpubl. data). To our knowledge, the only other report of Scyphozoan consumption by green turtles in neritic habitats was also gathered via VTDR data (Heithaus et al. 2002b). Perhaps the large size and/or rapid digestion of gelatinous prey inhibit recovery via conventional dietary analyses. If so, animal-borne imagery may be the best tool for revealing consumption of such items. However, we acknowledge that, while VTDR systems may be superior for determining the presence of diet items and their mode of intake (i.e. directed versus incidental), other techniques such as stable isotope analysis (Godley et al. 1998) and fatty-acid analysis (Seaborn et al. 2005) are more effective for determining the relative energetic importance of ingested foods.

Through deployment of VTDRs, we learned that green turtles engage in stationary and active benthic foraging at depths of 3.0 to $32.5 \mathrm{~m}$, and they actively forage in the midwater column at depths of 3.0 and 5.0 m (Table 2, Fig. 7). Stationary foraging by green turtles over nearshore algae pastures has been reported at other sites (e.g. Bjorndal 1997), but no studies have described this foraging tactic in deeper waters away from herbivorous food patches. The offshore benthic foraging peak at 20.0 to $29.9 \mathrm{~m}$ (Fig. 7) is likely tied to the distribution of the yellow-polyp black coral fields that start at ca. $17 \mathrm{~m}$ depth (J. Seminoff pers. obs.). However, the benthic sifting of small-particle anoxic substrate at depths $>30 \mathrm{~m}$ indicates that green turtles access even deeper sites on occasion. Although some offshore foraging, particularly in the midwater column, may be an opportunistic response to prey availability, this is clearly not always the case, as indicated by the repeated visits to these sites (e.g. Fig. 6d). Nevertheless, foraging was infrequent in the deepest portions of the study area (Fig. 7), thus providing further evidence that shallow zones provide the most important foraging habitat for green turtles.

\section{Resting behaviour}

Continuous resting sequences have been reported in numerous earlier studies (eg. van Dam \& Diez 1996, Hays et al. 2000, Makowski et al. 2006), but our study is the first to show episodic resting dives by sea turtles. Assuming that dive duration is inversely related to metabolic activity (Prange 1976), the longer duration of episodic resting dives versus foraging and movement Type 1 dives indicates that green turtle metabolic rates slowed somewhat. There was little variation between mean episodic resting dive durations (11.9 min) and continuous resting dive durations (13.1 $\mathrm{min})$, and the mean depth of these resting strategies was almost identical (20.9 $\mathrm{m}$ and $20.2 \mathrm{~m}$, respectively; Table 3). Therefore, episodic resting may afford the same perdive energetic savings as continuous resting. These parallels, coupled with the similarity in habitats visited during episodic and continuous resting, also suggest that turtles engaging in resting behaviour seek similar shelter sites, regardless of the resting duration.

Resting in close association with marine algae pastures, black coral patches and boulder fields indicates that vertical features are a key component of resting microsites for green turtles in Bahía de los Angeles. We believe there are at least 2 possible explanations for this. First, the location of resting may be an attempt to avoid strong currents, which could negatively affect the turtle's ability to remain motionless and conserve energy: Bahía de los Angeles has a vertical tidal flux of $>2 \mathrm{~m}$ and lateral current flow in excess of $12 \mathrm{~km} \mathrm{~h}^{-1}$ (Bray \& Robles 1991; J. Seminoff unpubl. data). Second, by diving to 
the seafloor and resting near vertical features, green turtles presumably minimize their susceptibility to predation. Sharks are the primary predator of sea turtles (e.g. Heithaus et al. 2002a), and observations of missing flippers and bite marks on green turtles captured locally indicate shark predation in the region (Seminoff et al. 2003).

Although green turtles show affinity to vertical features during resting in benthic habitats, they were never observed to wedge between boulders or below overhanging ledges, thus indicating that either neutral or negative buoyancy was achieved. However, assuming that the relationship between turtle size and lung volume is relatively constant among disparate green turtle populations, the relatively small size of green turtles examined in this study suggests that green turtles exceeded the maximum depths at which neutral buoyancy could be achieved. Whereas Hays et al. (2000) hypothesized that green turtles at Ascension Island (109.0 to $127.7 \mathrm{~cm}$ curved carapace length [CCL]) maintain neutral buoyancy at depths no greater than $19.0 \mathrm{~m}$, the green turtles in this study rested at depths of up to $26.0 \mathrm{~m}$ despite substantially smaller size (range $=\sim 68.7$ to $102.5 \mathrm{~cm}$ CCL based on the conversion CCL $=(1.0363$ $\times \mathrm{SCL})+2.2464$; Seminoff et al. 2003). Although we cannot rule out the possibility that the VTDR affected resting depths in some way, the deeper depths observed in this study suggest that buoyancy control may not be a universal strategy employed by resting green turtles. The lack of a correlation between turtle size and resting depth found in this study supports this theory, and it suggests that resting depth by green turtles is a result of active habitat selection rather than a consequence of lung volume.

\section{Does the Crittercam record natural behaviours?}

Because instrumented turtles were studied for the purpose of extrapolation to untagged individuals, it is important to consider the extent to which results are biased by the effects of the Crittercam system. Although there is a possibility that some underwater behaviours were altered due to the presence of the relatively large instrument, we tried to minimize such effects by designing the housing with the most hydrodynamically efficient shape possible, and by counter-weighting the attachment base plate to create a neutrally buoyant unit. The negligible nature of the Crittercam's impacts on green turtle underwater activities was evidenced by the following facts: (1) a comparison demonstrated that the mean swim speeds of the 11 tracked turtles were consistent with those from 8 turtles of similar size tracked in the study area with ultrasonic telemetry (2sample $t$-test, $\mathrm{p}=0.94 ; \mathrm{J}$. Seminoff unpubl. data); (2) the dive profiles and depths achieved during dives were consistent with previous studies of green turtle dive behaviour (J. Seminoff unpubl. data); and (3) normal daily activities such as foraging and resting were exhibited by green turtles within minutes of release. In addition, previous studies employing the Crittercam have also shown negligible effects of the units on behaviour. Parrish et al. (2000) found that Hawaiian monk seals foraged and dived normally with a Crittercam attached for up to $3 \mathrm{~d}$. Heithaus et al. (2001) reported that Crittercam-equipped tiger sharks (Galeocerdo cuvier), showed no abnormal behaviour with respect to habitat selection, foraging behaviour or swim speed.

\section{CONCLUSIONS}

Our results include 2 important findings that bear on the study of underwater activity by sea turtles. First, the integration of time-depth plots with video indicates that a single dive profile may reflect more than one behaviour. This variability suggests that caution should be exercised when ascertaining activity solely based on dive patterns. Second, the observation that green turtles feed and rest at variable depths and in multiple habitats indicates that the empirical view afforded by exclusive use of time-depth plots is insufficient for determining the interactions of sea turtles with benthic substrates, particularly in areas with a complex habitat mosaic. This underscores the value of image data for depicting the interactions of turtles with diverse habitats. Although these are helpful advances, it is important to note that our results are heavily biased toward daytime activity (98\% of all video) of larger turtles (mean $=75.1 \pm 4.1 \mathrm{~kg}$ ), the result of the VTDR's inability to monitor during low-light conditions and its relatively large size. To facilitate broader studies, we encourage the wider application of night-vision VTDR systems as well as the continued miniaturization of these and other animal-borne electronic devices. The use of other tools, such as flipper-beat sensors (Hays et al. 2004), beak-movement sensors (Hochscheid et al. 2005), and stomach-temperature transmitters (Andrews 1998), will also further elucidate the behaviours of sea turtles in marine habitats.

Acknowledgements. We gratefully acknowledge M. Blanco, S. Collins, J. Gilmore, A. Lusk, A. McDermott, S. PrestiLantry, R. Redecker, A. Resendiz, M. Rosini, T. Smith, and L. Yarnell for their assistance in the field. Special thanks go to the National Geographic Special Projects team, especially K. Abernathy, M. Bakhtiari, K. Fuchs, S. Snider, and L. Barre for technical assistance. T. Eguchi, S. Hochscheid, M. Tiwari and 3 anonymous reviewers gave helpful comments on earlier drafts of this manuscript. This work was supported by Earth- 
watch Institute, National Geographic Remote Imaging, and Wallace Research Foundation. Research was authorized by the Secretaría de Medio Ambiente, Recursos Naturales y Pesca (Permit numbers 150496-213-03, 280597-213-03, 190698-213-03, and 280499-213-03) and the Secretaría de Medio Ambiente y Recursos Naturales (Permit number SGPA/DGVS/002). All turtle handling was in accordance with Institutional Animal Care and Use Committees at the University of Arizona and the University of Florida.

\section{LITERATURE CITED}

Andrews RD (1998) Instrumentation for the remote monitoring of physiological and behavioral variables. J Appl Physiol 85:1974-1981

Bjorndal KA (1997) Foraging ecology and nutrition of sea turtles. In: Lutz PL, Musick JA (eds) The biology of sea turtles. CRC Press, Boca Raton, FL, p 199-232

Bray NA, Robles JM (1991) Physical oceanography of the Gulf of California. In: Dauphin JP, Simoneit BRT (eds) The Gulf and peninsular province of the Californias. American Association of Petroleum Geologists, Tulsa, OK, p 511-533

Brill RW, Balazs GH, Holland KN, Chang RKC, Sullivan S, George JC (1995) Daily movements, habitat use, and submergence intervals of normal and tumor-bearing juvenile green turtles (Chelonia mydas L.) within a foraging area in the Hawaiian Islands. J Exp Mar Biol Ecol 185:203-218

Godley BJ, Thompson DR, Waldron S, Furness RW (1998) The trophic status of marine turtles as determined by stable isotope analysis. Mar Ecol Prog Ser 166:277-284

Hays GC, Adams CR, Broderick AC, Godley BJ, Lucas DJ, Metcalfe JD, Prior AA (2000) The diving behaviour of green turtles at Ascension Island. Anim Behav 59: 577-586

Hays GC, Åkesson S, Broderick AC, Glen F and 5 others (2001) The diving behaviour of green turtles undertaking oceanic migration to and from Ascension Island: dive durations, dive profiles and depth distribution. J Exp Biol 204:4093-4098

Hays GC, Metcalfe JD, Walne AW, Wilson RP (2004) First records of flipper beat frequency during sea turtle diving. J Exp Mar Biol Ecol 303:243-260

Heithaus MR, Marshall GJ, Buhleier BM, Dill LM (2001) Employing Crittercam to study habitat use and behavior of large sharks. Mar Ecol Prog Ser 209:307-310

Heithaus MR, Frid A, Dill LM (2002a) Shark-inflicted injury frequencies, escape ability, and habitat use of green and loggerhead turtles. Mar Biol 140:229-236

Heithaus MR, McLash JJ, Frid A, Dill LM, Marshall GJ (2002b) Novel insights into green sea turtle foraging behavior using animal-borne video cameras. J Mar Biol Assoc UK 82:1049-1050

Hochscheid S, Wilson RP (1999) A new method for the determination of at-sea activity in sea turtles. Mar Ecol Prog Ser 185:293-296

Hochscheid S, Godley BJ, Broderick AC, Wilson RP (1999) Reptilian diving: highly variable dive patterns in the green turtle Chelonia mydas. Mar Ecol Prog Ser 185:101-112

Hochscheid S, Maffucci F, Bentivegna F, Wilson RP (2005) Gulps, wheezes, and sniffs: how measurement of beak movement in sea turtles can elucidate their behaviour and ecology. J Exp Mar Biol Ecol 316:45-53

Houghton JDR, Woolmer A, Hays GC (2000) Sea turtle diving and foraging behaviour around the Greek island of Kefalonia. J Mar Biol Assoc UK 80:761-762

Houghton JDR, Broderick AC, Godley BJ, Metcalfe JD, Hays GC (2002) Diving behaviour during the internesting interval for loggerhead turtles (Caretta caretta) nesting in Cyprus. Mar Ecol Prog Ser 227:63-68

Makowski C, Seminoff JA, Salmon M (2006) Home range and habitat use of juvenile Atlantic green turtles (Chelonia mydas L.) on shallow reef habitats in Palm Beach, Florida, USA. Mar Biol 148:1167-1179

Minamikawa S, Naito Y, Uchida I (1997) Buoyancy control of the loggerhead turtle, Caretta caretta. J Ethol 15:109-118

Musick JA, Limpus CJ (1997) Habitat utilization and migration in juvenile sea turtles. In: Lutz PL, Musick JA (eds) The biology of sea turtles. CRC Press, Boca Raton, FL, p 137-163

Parrish FA, Craig MP, Ragen TJ, Marshall GJ (2000) Identifying diurnal foraging habitat of endangered Hawaiian monk seals using a seal-mounted video camera. Mar Mamm Sci 16:392-412

Prange HD (1976) Energetics of swimming of a sea turtle. J Exp Biol 64:1-12

Reina RD, Abernathy KJ, Marshall GJ, Spotila JR (2005) Respiratory frequency, dive behaviour and social interactions of leatherback turtles, Dermochelys coriacea during the internesting interval. J Exp Mar Biol Ecol 316:1-16

SAS Institute (1996) A guide to statistical and data analysis using JMP and JMP IN software. Duxbury Press, Belmont, NY

Schmid JR, Bolten AB, Bjorndal KA, Lindberg WJ (2002) Activity patterns of Kemp's ridley turtles, Lepidochelys kempii, in the coastal waters of the Cedar Keys, Florida. Mar Biol 140:215-228

Seaborn GT, Moore MK, Balazs GH (2005) Depot fatty acid composition in immature green turtles (Chelonia mydas) residing at two near-shore foraging areas in the Hawaiian Islands. Comp Biochem Physiol B 140:183-195

Seminoff JA, Resendiz A, Nichols WJ (2002a) Home range of the green turtle Chelonia mydas at a coastal foraging ground in the Gulf of California, México. Mar Ecol Prog Ser 242:253-265

Seminoff JA, Resendiz A, Nichols WJ (2002b) Diet of the East Pacific green turtle, Chelonia mydas, in the central Gulf of California, México. J Herpetol 36:447-453

Seminoff JA, Jones TT, Resendiz A, Nichols WJ, Chaloupka MJ (2003) Monitoring of green turtles (Chelonia mydas) at a foraging habitat in the Gulf of California, Mexico: multiple indices describe population status. J Mar Biol Assoc UK 83:1355-1362

Southwood AL, Reina RD, Jones VS, Jones DR (2003) Seasonal diving patterns and body temperatures of juvenile green turtles at Heron Island, Australia. Can J Zool 81: 1014-1024

Thayer GW, Engel DW, Bjorndal KA (1982) Evidence for short circuiting of the detritus cycle of seagrass beds by the green turtle, Chelonia mydas. J Exp Mar Biol Ecol 62:173-183

van Dam RP, Diez CE (1996) Diving behavior of immature hawksbills (Eretmochelys imbricata) in a Caribbean cliffwall habitat. Mar Biol 127:171-178 
Appendix 1. Summary of VTDR deployments on green turtles in Bahía de los Angeles between August 1997 and June 2002. SCL $=$ straight carapace length $(\mathrm{cm}) .(\bullet)$ Successful collection of dive data and video. See Fig. 1 for location of initial release site of each deployment

\begin{tabular}{|c|c|c|c|c|c|c|c|}
\hline Deployment number & Date & Site & Turtle ID & $\mathrm{SCL}(\mathrm{cm})$ & Weight (kg) & Dive data & Video \\
\hline CM-01 & 15 Aug 2097 & 9 & BLA 219 & 77.3 & 67.3 & & \\
\hline CM-02 & 19 Aug 1997 & 5 & BLA 220 & 70.1 & 61.4 & - & - \\
\hline CM-03 & 24 Sep 1998 & 6 & BLA 339 & 80.2 & 81.8 & - & \\
\hline CM-04 & 26 Sep 1998 & 3 & BLA $231^{a}$ & 94.7 & 111.8 & $\bullet$ & $\bullet$ \\
\hline CM-05 & 28 Sep 1998 & 3 & BLA 340 & 74.0 & 54.1 & $\bullet$ & - \\
\hline CM-06 & 30 Sep 1998 & 6 & BLA 342 & 90.7 & 108.6 & $\bullet$ & $\bullet$ \\
\hline CM-07 & 30 Sep 1998 & 6 & BLA 224 & 74.6 & 53.2 & $\bullet$ & $\bullet$ \\
\hline CM-08 & 01 Oct 1998 & 6 & BLA 343 & 85.1 & 84.5 & $\bullet$ & - \\
\hline CM-09 & 13 Sep 1999 & 6 & BLA 137 & 89.4 & 101.8 & & \\
\hline CM-10 & 14 Sep 1999 & 6 & BLA 434 & 80.2 & 70.9 & & \\
\hline CM-11 & 15 Sep 1999 & 6 & BLA 433 & 73.8 & 59.1 & $\bullet$ & \\
\hline CM-12 & 16 Sep 1999 & 6 & BLA 432 & 64.1 & 38.6 & - & - \\
\hline CM-13 & 18 Sep 1999 & 1 & BLA $422^{\mathrm{a}}$ & 66.6 & 47.7 & - & \\
\hline CM-14 & 19 Sep 1999 & 6 & BLA 425 & 81.4 & 77.3 & - & - \\
\hline CM-15 & 21 Sep 1999 & 6 & BLA 438 & 78.9 & 64.5 & $\bullet$ & $\bullet$ \\
\hline CM-16 & 22 Sep 1999 & 6 & BLA 329 & 89.0 & 90.5 & - & - \\
\hline CM-17 & 28 Jun 2000 & 6 & BLA 426 & 88.7 & 111.4 & - & \\
\hline CM-18 & 29 Jun 2000 & 6 & BLA 511 & 68.1 & 40.9 & & \\
\hline CM-19 & 02 Jul 2000 & 6 & BLA 512 & 85.6 & 73.2 & - & \\
\hline CM-20 & 11 Jul 2000 & 4 & BLA 515 & 77.5 & 54.5 & - & - \\
\hline CM-21 & 18 Jul 2000 & 6 & BLA 516 & 77.5 & 68.2 & - & - \\
\hline CM-22 & 24 Jul 2000 & 6 & BLA 518 & 70.5 & 49.5 & $\bullet$ & - \\
\hline CM-23 & 28 Jul 2000 & 2 & BLA $231^{a}$ & 96.7 & 119.1 & $\bullet$ & - \\
\hline CM-24 & 26 Jul 2000 & 4 & BLA 406 & 85.7 & 85.9 & - & - \\
\hline CM-25 & 02 Aug 2000 & 5 & BLA 519 & 81.4 & 79.5 & $\bullet$ & $\bullet$ \\
\hline CM-26 & 11 Aug 2000 & 6 & BLA 520 & 82.1 & 75.0 & • & - \\
\hline CM-27 & 13 Aug 2000 & 3 & BLA 521 & 71.6 & 56.8 & - & - \\
\hline CM-28 & 15 Aug 2000 & 2 & BLA $422^{\mathrm{a}}$ & 68.4 & 50.0 & - & - \\
\hline CM-29 & 16 Aug 2000 & 3 & BLA 522 & 64.9 & 38.6 & • & - \\
\hline CM-30 & 17 Aug 2000 & 8 & BLA 523 & 88.0 & 107.7 & - & - \\
\hline CM-31 & 18 Aug 2000 & 8 & BLA 525 & 95.7 & 120.5 & - & - \\
\hline CM-32 & 23 Aug 2000 & 8 & BLA 524 & 70.2 & 45.9 & - & - \\
\hline CM-33 & 24 Jul 2001 & 7 & BLA 614 & 82.0 & 72.3 & - & \\
\hline CM-34 & 01 Aug 2001 & 7 & BLA 430 & 71.0 & 64.8 & - & $\bullet$ \\
\hline CM-35 & 03 Aug 2001 & 3 & BLA 601 & 86.1 & 115.5 & $\bullet$ & - \\
\hline CM-36 & 20 Jun 2002 & 7 & BLA 706 & 83.5 & 115.5 & • & \\
\hline
\end{tabular}

Editorial responsibility: Otto Kinne (Editor-in-Chief), Oldendorf/Luhe, Germany
Submitted: November 24, 2005; Accepted: March 2, 2006 Proofs received from author(s): August 28, 2006 